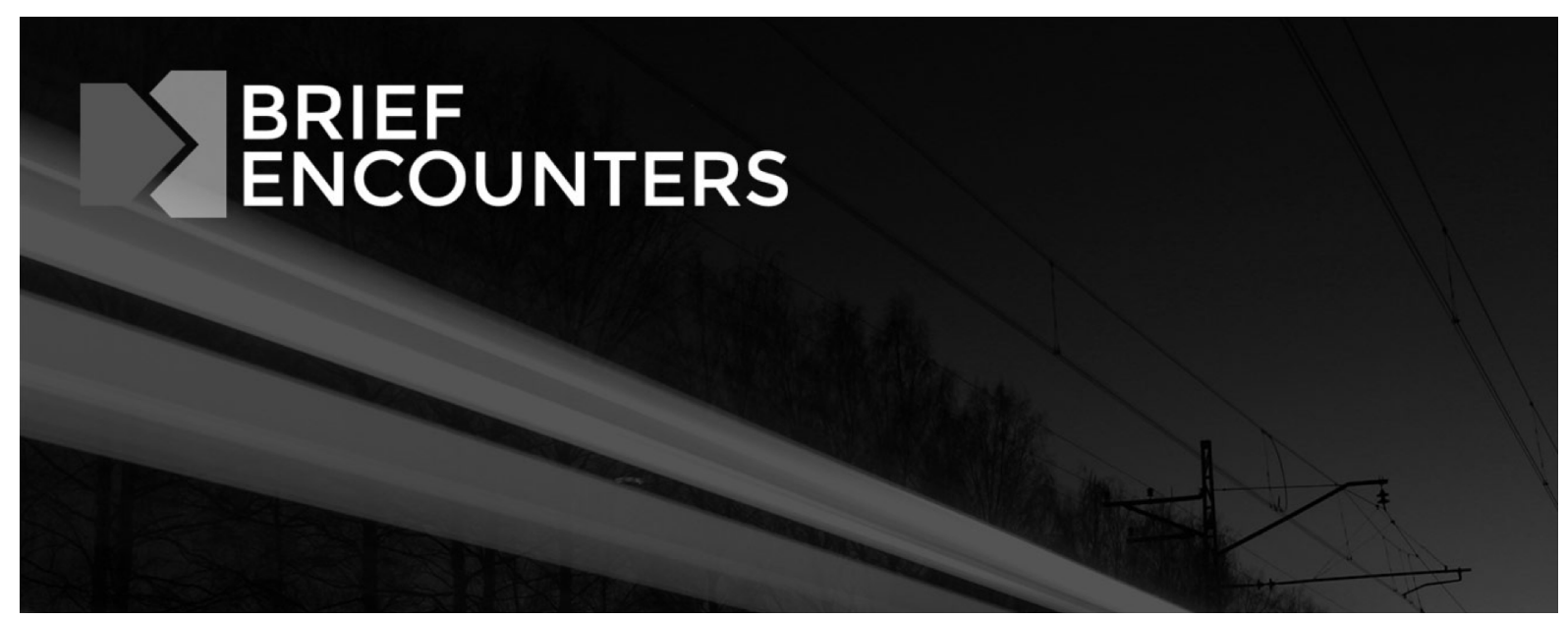

ISSN 2514-0612

Journal homepage: http://briefencounters-journal.co.uk/BE

Nightcore and the Virtues of Virtuality

Author(s): Emma Winston

Email: e.winston@gold.ac.uk

Source: Brief Encounters Vol.1, No. 1 (Feb 2017)

URL: http://briefencounters-journal.co.uk/BE/article/view/20/

DOI: http://dx.doi.org/10.24134/be.v1i1.20

(C) Emma Winston, 2017

License (open-access): This is an open-access article distributed under the terms of the Creative Commons Attribution License 4.0, which permits unrestricted use, distribution, and reproduction in any medium, provided the original work is properly cited. No warranty, express or implied, is given. Nor is any representation made that the contents will be complete or accurate or up to date. The publisher shall not be liable for any actions, claims, proceedings, demand or costs or damages whatsoever or howsoever caused arising directly or indirectly in connection with or arising out of the use of this material.

Brief Encounters is an open access journal that supports the dissemination of knowledge to a global readership. All articles are free to read and accessible to all with no registration required. For more information please visit our journal homepage: http://briefencounters-journal.co.uk/BE. 


\section{Nightcore and the Virtues of Virtuality}

\section{Emma Winston}

In her writings on the early punk scene, Helen Reddington coins the concept of a 'microsubculture', a small music scene within a broader subculture which is valuable because it allows for the close study of musicians who might otherwise be erased from canonical discourse. By examining the small-scale, in the form of bands and artists who might seem insignificant, Reddington sheds light upon the treatment of women in both punk and the wider music industry. ${ }^{1}$ Reddington's concept of the micro-subculture focuses upon geographically local music scenes; however, George E. Marcus proposes that, beginning in the twilight years of the twentieth century, ethnographic research (that is, the research of people, their customs, and cultures) moved dramatically away from the single to the multi-sited locale, which presumably became still more pronounced in the wake of the internet. ${ }^{2}$ In this article I will explore 'nightcore', a previously academically unexamined music scene, which exists entirely online and which operates as a multi-sited micro-subculture within the broader context of internet-based electronic music. Nightcore is as remarkable for its do-it-yourself attitude to de-skilling electronic production, as for its virtual-centric, yet profoundly social approach to track dissemination and community; by presenting it here, I hope to prompt further research and discussion around both the genre itself, and, more broadly, online musical communities and the work created within them.

Nightcore is a contested term, and the history of the scene and genre is multi-faceted. The first use of the name online was in 2002 by Norwegian teenagers Thomas Nilsen and

\footnotetext{
${ }^{1}$ Helen Reddington,'“Lady" Punks in Bands: A Subculturette?', in The Post-Subcultures Reader, ed. by David Muggleton (Oxford: Berg, 2003), pp. 231-251 (pp. 246-248).

2 George E. Marcus, 'Ethnography in/of the World System: The Emergence of Multi-Sited Ethnography', Annual Review of Anthropology, 24 (1995), 95-117 <https://doi.org/10.1146/annurev.an.24.100195.000523> [accessed 25 July 2016] (pp. 96-101).
} 
Steffen Soderholm, who released five albums of sped-up (and correspondingly pitch-shifted upward) electronic trance under the band name Nightcore. ${ }^{3}$ With the exception of a few songs, Nilsen and Soderholm's work vanished almost without trace when their website was removed from the internet in 2003. ${ }^{4}$ These extant songs began to appear on YouTube and the now defunct peer-to-peer file-sharing client LimeWire, often soundtracking edits of footage from Japanese animated cartoons. ${ }^{5}$ In 2008 (the earliest uploader I have been able to locate is 'Maikel', who lists Nilsen and Soderholm as his sole musical influences on his Facebook page), speed edits of other trance and Eurodance songs tagged as 'nightcore' began to appear on YouTube, frequently still paired with images from Japanese animation. ${ }^{6}$ Nightcore speed edits of trance songs continue to thrive as a genre, particularly on YouTube, but the term has also since become significantly broader in its scope.

In 2011 a 'nightcore'-tagged, sped-up edit of a song by rock band Evanescence was uploaded to YouTube, representing the first step of the genre into its stylistically omnivorous present-day form. ${ }^{7}$ Although several early uploaders, including Maikel, consider non-trance remixes of this kind to be 'fake nightcore', media platform Nest HQ (one of only a few publications to have covered the scene) suggests that the broadening of the term was also a crucial catalyst in attracting fans to the genre. ${ }^{8}$ Today, nightcore refers most broadly to the production of hyper-fast dance-pop music with pitched-up vocals which, crucially, is based around tracks lifted wholesale from mainstream pop, rock, and electronic dance music (EDM) timestretched and pitch-shifted upwards, often, but not always, with additional original production. ${ }^{9}$ When I refer to nightcore

\footnotetext{
4 Jonah Berry, 'Nest HQ's Guide to Nightcore', Nest HQ (August 7 2015) <http://nesthq.com/nightcore> [accessed 21 July 2016] (para. 6 of 22).

4 Kirby, 'What is Nightcore?', Nightcore Universe (August 8 2011) <http://www.nightcoreuniverse.net/viewtopic.php? $\mathrm{f}=17 \& \mathrm{t}=930>$ [accessed 25 July 2016].

${ }^{5}$ Berry (para. 5 of 22 ).

6 Maikel631, Amazing Nightcore and Trance (online video recording), YouTube, 25 July 2016, <https://www.youtube.com/ user/Maikel6311> [accessed 25 July 2016].

7 Berry (para. 9 of 22).

8 Ibid. (para. 9-10 of 22).

9 Heath Harshman, 'Why We Welcome Nightcore As The Next Breakout Genre', Dance Music Northwest (July 25 2015) <http:// dancemusicnw.com/why-we-welcome-nightcore-as-the-next-breakout-genre/> [accessed 25 July 2016].
} 
throughout this article, then, I do so in this stylistically broader sense. As a living, breathing musical scene of several thousand individuals worldwide, nightcore enthusiastically plunders and reworks contemporary popular music, blurs the boundaries between its artists and its fans to the point of nonexistence, disseminates its musical commodities almost exclusively online, and both relies upon, and reflects back in its sonic content, the flow of information afforded by the internet.

\section{Style, Speed and Society}

'Nightcore was completely inevitable, [...] All human beings have ever wanted to do is go faster', proposes Simon Whybray, host of monthly internet broadcast Radio Jack, which specialises in nightcore and what Whybray refers to as 'hyper-pop', essentially an umbrella term for fast-paced, frenetic pop music. ${ }^{10}$ Reflecting Reddington's suggestion that a microsubculture can inform a researcher about broader musical and cultural trends, Whybray implies that nightcore, for all its niche appeal, is a product of a core societal trait. Speed is central, even genre-defining, to nightcore. Los Angeles-based DJ, Ducky (one of only two artists along with DJ Fan Fiction that I was able to locate who regularly play nightcore in offline locations) describes the genre in an interview with Dummy Magazine simply as 'other people's songs that have been sped up. [S]ome people add additional production, extra percussion, etc. but that's the foundation'.11 She also suggests, however, that 'it's going to become a broader term and we'll start seeing [...] original productions inspired by the sound of nightcore in its current form.'12 The form to which Ducky refers is fast - usually upwards of 160 beats per minute - with pitch-shifted vocals made higher than their original source material, and lead synths which are often delicate and very high-pitched, counterbalancing the pumping bass and kick drum common to most electronic dance music. The opening of

\footnotetext{
${ }^{10}$ Simon Whybray, cited in Berry (para. 16 of 22).

11 Morgan Neiman, quoted in Kristy Barker, 'Ducky: "Nightcore is the nicest scene I've ever participated in",' Dummy Magazine (23 March 2016) <http://www.dummymag.com/features/ducky-nightcore-interview> [accessed 25 July 2016] (para. 5 of 17).

12 Ibid. (para. 5 of 17).
} 
EasyFun's EasyMix is an excellent example, adding fragile, hard-panned xylophone samples to Ariana Grande's Break Free in its introduction before being joined by more conventionally trance-like rhythmic supersaw synths (a tone made up of several detuned sawtooth sound waves stacked together, frequently heard in classic trance music). ${ }^{13}$ For all that nightcore borrows from EDM, then, with its fat kick-drum tones and synthesiser stabs, there is often a sense of fragility and thinness particularly to the genre's lead melodic elements; Babeisland's all i need, Fan Fiction's f4k3, and Henrik The Artist's Just Peachy (an early example of the 'original nightcore' Ducky mentions) exemplify this tendency. ${ }^{14}$ The overall effect falls somewhere between trance and pop, with an emphasis on high, bright treble frequencies which are presumably originally a product of pitching up existing songs, but have become a feature of the genre in their own right, giving a 'sped-up' feel even to original elements of tracks added by the artist in question.

The centricity of speed to nightcore is multi-stranded, and understanding it within this particular micro-subculture may shed light upon others for both their similarities and their differences. Grafton Tanner writes at length in his book Babbling Corpse about the cultural significance of the 'vaporwave' micro-subculture which, in a curious proto-reflection of nightcore, is marked by the deconstruction of songs by slowing and pitching them down, often using 1980s soft rock or easy-listening works as its source material rather than mainstream contemporary pop, which gives a feel reminiscent of 'muzak', the bland background music often heard in commercial and retail contexts. Vaporwave's purpose, suggests Tanner, is 'to reframe muzak [...] to remind listeners of its omnipresence and, therefore, to wake us up to the corporatist society in which we are trapped'. 15 This rejection of

\footnotetext{
13 EasyFun, easyFun - easyMix (online audio recording), SoundCloud, 30 June 2016, <https://soundcloud.com/easyfun/ easymix> [accessed 25 July 2016].

14 Babeisland, all i need (online audio recording), SoundCloud, 30 June 2015, <https://soundcloud.com/babeisland/all-ineed> [accessed 25 July 2016]; Fan Fiction, f4k3 (online audio recording), SoundCloud, 28 June 2016, <https:// soundcloud.com/fanfiction/f4k3> [accessed 25 July 2016]; Henrik The Artist, Just Peachy (online audio recording), SoundCloud, 14 November 2015, <https://soundcloud.com/henrik-the-artist/just-peachy> [accessed 25 July 2016].

${ }^{15}$ Grafton Tanner, Babbling Corpse: Vaporwave and the Commodification of Ghosts (London: Zero Books, 2016), pp. 40-41.
} 
corporate ideology is also present in the independent, faceless, internet-based means by which vaporwave is disseminated and shared. ${ }^{16}$ Tanner draws links between slowed-down tracks and Derrida's concept of hauntology, the 'haunting' of the present by the past, which vaporwave achieves by emphasising 'the eeriness of hauntological breakdown' through audio glitches and altered sample rates. ${ }^{17}$ Nightcore is also marked by both of these latter characteristics, but, because its source material is sped up rather than slowed down, it possesses none of vaporwave's eeriness or muzak-like qualities. Where vaporwave evokes unease and stasis, nightcore is frenetic, pulsing with forward motion, and often joyful, bearing a strong stylistic resemblance to the 1990 s originals-based genre, happy hardcore. ${ }^{18}$

What can vaporwave and nightcore's approaches to speed editing tell us about their relationship with broader society? Accelerationist philosophy holds that by speeding up and saturating the uprooting and destructive processes of capitalist society, its systems will selfdestruct; by repurposing the tools of capitalism and embracing rapid technological change, the status quo is turned upon itself. Vaporwave, in Tanner's words, 'mirror(s) the anticipation and dread of the accelerating future', and positions late capitalism as 'a fantasy world where life accelerates to the point of stasis'; it is critical of the trappings of capitalism and the rapid pace of their development. ${ }^{19}$ Nightcore seems almost uncritically accelerationist, both temporally and ideologically, in comparison. Rejecting stasis entirely and emphasising constant kinetic motion, broken up only by the soars and drops which philosopher Robin James links to contemporary society's valorisation of emotional and social resilience in mainstream EDM-influenced pop, it recycles not long-forgotten adult contemporary and advertorial music, but Top 40 chart hits and viral underground dance tracks. ${ }^{20}$ YouTube channel Pepsi Cola, which publicises music videos by emerging nightcore artists, outright

\footnotetext{
16 Ibid., p. 45.

17 Ibid., pp. 10-12.

${ }^{18}$ Berry suggests that the two genres are often confused for one another, see Berry (para. 8 of 22).

${ }^{19}$ Tanner, p. 48.

${ }^{20}$ Robin James, Resilience \& Melancholy: Pop Music, Feminism, Neoliberalism (London: Zero Books, 2015), pp. 28-37.
} 
borrows its name, logo, and comments from its namesake's advertising campaigns, and does so in an entirely straight-faced manner, without additional commentary or political overtones (its comment history on both YouTube and SoundCloud is made up entirely of unedited Pepsi slogans). ${ }^{21}$ If vaporwave dreads the accelerating advancement of late capitalism, on its surface nightcore seems to embrace it; as Whybray suggests, it is the musical outcome of the human desire to 'go faster'.

Nightcore's use of the corporate mainstream, as in accelerationist philosophy, can also be read as strongly countercultural, and the genre's broader relationship with late capitalism is more ambivalent than it may seem on the surface. Like vaporwave, nightcore is distributed primarily through do-it-yourself online distribution platforms SoundCloud and Bandcamp, almost always for free or otherwise pay-what-you-can, with little to no profit being made. Sarah Thornton describes 'subcultural capital', the accumulation of relevant knowledge and commodities within a given subcultural group, as key to raising an individual's status within that subculture, and suggests that even the most niche forms of this capital can often be pragmatically converted into 'a variety of occupations and incomes'.22 At the time of writing, however, it seems to be the case that few, if any, nightcore producers are receiving occupational or financial benefits from their participation in the subculture, perhaps in part because of the copyrighting implications that come from lifting source material wholesale from existing tracks. ${ }^{23}$ It is also worth noting that nightcore's recontextualisation of its source material is intended to be recognised as plagiaristic; a popular sentiment amongst commenters and producers is that their nightcored tracks simply sound 'better sped up', suggesting a breakdown between expert and amateur producer. ${ }^{24}$ Even the

\footnotetext{
${ }^{21}$ Pepsi Cola, YouTube, <https://www.youtube.com/channel/UCxNBvCX1cy5f8whl07mRCIA> [accessed 25 July 2016] (the name of this YouTube channel has since been changed to Not Pepsi); Pepsi, SoundCloud, <https://soundcloud.com/ not_pepsi> [accessed 25 July 2016].

${ }^{22}$ Sarah Thornton, Club Cultures: Music, Media, and Subcultural Capital (Cambridge: Polity, 1995), p. 12.

23 Thornton, p. 203.

${ }^{24}$ For examples, see Berry (para. 7 of 22); Neiman quoted in Barker (para. 5 of 17); descriptions to DJ Clickbait, n3v3r fOrg3t u (online audio recording), SoundCloud, 11 June 2016, <https://soundcloud.com/djclickbait/n3ver-fOrg3t-u> [accessed 25 July 2016]; Imran Khan, Fall Out Boy-Centuries (Sped Up To Right Amount) (online video recording), YouTube, 11 November 2014, <https:// www.youtube.com/watch?v=-qzWRnlYOdo> [accessed 25 July 25 2016].
} 
aforementioned Pepsi Cola channel uses the corporation's words, imagery and name on its YouTube page, but does not place even third-party adverts, common to most YouTube videos, on the videos it posts, setting it apart from the world's one hundred largest corporate brands, all of which have run ads on YouTube during the last year. ${ }^{25}$ Nightcore performs the removal and reappropriation of musical and aesthetic source material from the hands of large-scale record labels and music industry leaders, in a complicated entanglement of admiration and disrespect. By examining the micro-subculture's attitude to the capitalist system in which it originates, we can identify nightcore enacting a literal seizure of the means of production, turning the trappings of corporate ideology into a distorted, caricature-like version of itself by pushing it to its fast-paced extreme.

Placing speed at the very centre of the genre's aesthetic markers also allows a low barrier for entry into the scene as a producer. Since, as Ducky says, in its most basic form a nightcore production is simply a sped-up and correspondingly pitched-up song, it can allow young and inexperienced producers to be encouraged, viewed and treated as practitioners by their peers, including those within the micro-subculture who are making more elaborate and original productions. Based upon the overwhelmingly positive feedback simple speed-edited nightcore tracks receive on social media, subcultural capital and status do not seem to be tied exclusively to the addition of original compositional elements. Mike Challis advocates a similar 'back to front' approach in formalised teaching of electronic music to non-musicians, beginning with straightforward manipulation of pre-existing material before even beginning to add original elements, and considers DJing even in its most basic form to be an empowering creative act. ${ }^{26}$ Speeding up a track wholesale also permits the use of more basic digital audio workstation software, used for editing and mixing tracks, than does adding

\footnotetext{
25 'Statistics', YouTube, <https://www.youtube.com/yt/press/en-GB/statistics.html> [accessed 31 October 2016].

${ }^{26}$ Mike Challis, 'The DJ Factor: Teaching Performance and Composition from Back to Front', in Music Education with Digital Technology, ed. by Pamela Burnard John Finney (London: Continuum, 2009), pp. 65-75 (p. 65).
} 
original elements; the forum Nightcore Universe proposes Audacity as a first tool, which is both simple and open-source, meaning it can be obtained legally for free, lowering the barrier to entry for the subculture still further. ${ }^{27}$ One result of this is that virtually all nightcore fans, at least on SoundCloud, also appear to be nightcore producers themselves, posting their own mixes of tracks as well as reposting those they have enjoyed by others.

The increase in pitch, which is the most obvious side-effect of speeding up a nightcore track, is particularly noticeable in the context of vocals, since the recognisable formants (prominent frequencies allowing identification of vowel sounds) of the voice become distorted. David Feinberg, Lisa M. DeBruine, Benedict C. Jones and David I. Perrett have shown in perceptual studies of vocal pitch that higher-pitched voices tend to be associated with femininity and attractiveness, so one key aspect of nightcore is that its vocals are by definition feminised, regardless of the gender of the source material's original singer. ${ }^{28}$ The idea of femininity as default flies in the face of society at large. Deborah Tannen has written at length about the perception of masculinity and maleness as unmarked defaults, while femininity is always marked, in whatever form it takes. ${ }^{29}$ Nightcore's manipulation of vocals into something always and invariably feminised questions this, positioning itself as a polar opposite to the wider social default of masculinity. The feminine as default also seems to spill over into the visual aesthetics and perception of nightcore, as the 'album artwork' accompanying tracks is overwhelmingly in pale pastel colours, and comments referring to nightcore tracks as 'cute', 'kawaii' and 'adorable' are commonplace. ${ }^{30}$

\footnotetext{
27 Maikel, 'How to Nightcore a song! (NIGHTCORE TUTORIAL)', Nightcore Universe (8 May 2015) <http:// www.nightcoreuniverse.net/viewtopic.php?f=15\&t=142> [accessed 25 July 2016]; James Crook, Richard Ash, Roger Dannenberg, Benjamin Drung, Vaughan Johnson, Paul Licameli, Leland Lucius, and Martyn Shaw, 'Audacity: A Free Multi-Track Audio Editor and Recorder', Sourceforge (20 January 2016) <https://sourceforge.net/projects/audacity/> [accessed 25 July 2016].

28 David R. Feinberg, Lisa M. DeBruine, Benedict C. Jones, and David I. Perrett, 'The Role of Femininity and Averageness in Aesthetic Judgments of Women's Voices', Perception, 4.37 (2008), 615-623 <https://doi.org/10.1068/p5514> [accessed 25 July 2016] (pp. 619-621).

29 Deborah Tannen, 'Marked Women, Unmarked Men', The New York Times Magazine, 20 June 1993, pp. 1-4.

30 For examples in both artwork and comments, see Fan Fiction, 1 w4nt $\cup 2 \mathrm{KnOw}$ (online audio recording), SoundCloud, 9 April 2015, <https://soundcloud.com/fanfiction/1-w4nt-u-2-knOw> [accessed 25 July 2016]; Fan Fiction, b3g1n 4g41n (online audio recording), SoundCloud, 10 March 2015, <https://soundcloud.com/fanfiction/b3g1n-4g41n> [accessed 25 July 2016];

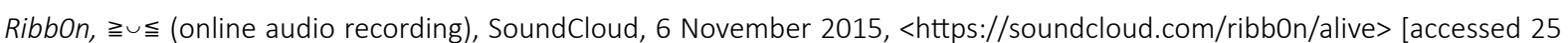
July 2016]; Underdog, internetparty \& underdOg - home (online audio recording), SoundCloud, 15 October 2015, <https:// soundcloud.com/underd0ge/home> [accessed 25 July 2016]; Internetparty, Last Time, (online audio recording), SoundCloud, 5 June 2015, <https://soundcloud.com/internetparty/last-time> [accessed 25 July 2016].
} 
Susana Loza refers to vocal manipulation in electronic music as a kind of 'technotransvestism', which questions the status quo because, in the words of Marjorie Garber, it 'denaturalizes, destabilizes, and defamiliarizes sex and gender signs'. ${ }^{31}$ Loza, applying Donna Haraway's Cyborg Manifesto to electronic dance's manipulation of bodily signals, highlights the gendered ambiguity which that manipulation can offer to a feminine subject, but she questions Haraway's optimism that 'the erasure of embodiment will magically unite us in universal understanding', considering the human-robot hybrid of the cyborg as more of an aesthetic starting point for feminism than an end goal. ${ }^{32}$ Nightcore's refusal to devalue the feminine does, however, seem to have had practical, real-world effects on the demographic of those who produce it; of those artists who choose to reveal their genders, a startling number are women, non-binary, or gender non-conforming, and it is telling that Ducky, perhaps the most media-visible member of the scene, is female. ${ }^{33}$ In Tara Rodgers' Pink Noises, artists Pamela $\mathrm{Z}$ and Beth Coleman both discuss the role of intimidation in keeping women out of the electronic music scene. ${ }^{34}$ By setting the initial bar for entry low, offering space for artistic development, positioning itself as a world away from the mainstream music industry, and not only defaulting to, but defining itself by femininity, while openly acknowledging and deconstructing its own flawed and utopian existence within the 'real world' of late capitalism, nightcore perhaps offers an alternative for individuals who may feel excluded from the wider world of electronic music-making. ${ }^{35}$

\footnotetext{
${ }^{31}$ Susana Loza, 'Sampling (Hetero)Sexuality: Diva-Ness and Discipline in Electronic Dance Music', Popular Music, 20.3 (2001), 349-357 <https://doi.org/10.1017/S0261143001001544> [accessed 25 July 2015] (pp. 354-355).

32 Ibid., pp. 355-356.

${ }^{33}$ Nina Agzarian, '\#WCW: Ducky', NLV Records (13 January 2016) <http://www.nlvrecords.com/wcw-ducky/> [accessed 25 July 2016].

34 Tara Rodgers, Pink Noises: Women on Electronic Music and Sound (Durham, North Carolina: Duke University Press, 2010), pp. 85-86.

35 Ibid., p.199.
} 


\section{Nightcore and Internet Micro-Media}

Staley Sharples of PressPlay labels nightcore 'the first music movement to be entirely formed online'. ${ }^{36}$ Although vaporwave hit a flurry of activity around 2014 , before the current era of pop-influenced nightcore I am discussing here, the genre's roots, name, and basic speedediting production techniques do date back to the early 2000s, positioning it at the very least amongst the earliest genres of internet-based music. ${ }^{37}$ Regardless of the finer details of the accuracy of Sharples's statement, she nonetheless highlights something vital to understanding the nightcore micro-subculture, namely its simultaneous emphasis on community and its relationship with the internet. Despite nightcore's fast pace and pounding rhythms rendering it ideal music for dancing, according to Ducky there are very few DJs playing nightcore in physical club locations, and, with few exceptions, the only place to hear nightcore is online. ${ }^{38}$ This is arguably unusual even in electronic genres with a strong online presence; Daniel Allington, Byron Dueck and Anna Jordanous suggest that particular cities occupy positions of significant privilege amongst SoundCloud producers at large, in part due to the influence of live DJing. ${ }^{39}$ The nightcore scene is notable, in contrast, for the fact that live shows take place almost exclusively via online radio, such as Simon Whybray's popular Radio Jack, and community-run station Datafruits. ${ }^{40}$

My experience of sitting in on the Non Stop NXC show on Datafruits on 16 th July 2016, showcasing seven nightcore producers from around the world, illustrated this phenomenon well. While this was only a single event, and a great deal of nightcore community activity

\footnotetext{
${ }^{36}$ Staley Sharples, 'PressPlaylist: Surati's NXC Sounds', PressPlay (29 April 2016) <https://wearepressplay.com/2016/04/29/ pressplaylist-suratis-nxc-sounds/> [accessed 25 July 2016].

37 Adam Harper, 'The Online Underground: A New Kind of Punk?', Resident Advisor (22 September 2014) <https:// www.residentadvisor.net/features/2137> [accessed 25 July 2016]; Berry (para. 3 of 22).

38 Neiman quoted in Barker (para. 10 of 17).

39 Daniel Allington, Byron Dueck and Anna Jordanous, 'Networks of Value in Electronic Music: SoundCloud, London, and the Importance of Place,' Cultural Trends, 24.3 (2015), 211-222 <https://doi.org/10.1080/09548963.2015.1066073> [accessed 25 July 2016] (pp. 218-220).

40 'Non Stop Pop', NTS Live <http://www.nts.live/shows/jack> [accessed 25 July 2016]; Datafruits FM <http://datafruits.fm/> [accessed 25 July 2016].
} 
takes place across less temporally immediate online spaces, such as SoundCloud comments or the Nightcore Universe forums, it encapsulated particularly well both nightcore's reliance on internet communication, and how the genre's erasure of physical embodiment can, as Loza and Haraway suggest, act as a jumping-off point for community inclusivity and, additionally, break down the barrier between producer and consumer. The Non Stop NXC show was billed for three hours, although in practice it overran by almost two hours (presumably permitted partly because of the non-physical nature of the 'venue'), and was advertised online in multiple timezones, in acknowledgement of the fact that both listeners and DJs were scattered across the globe. ${ }^{41}$ Despite the transparently non-local nature of the show and the website on which it was hosted, the experience was a profoundly social one. Datafruits, though first and foremost an internet radio station, uses only a thin bar at the top and bottom of its layout to display, respectively, information about the station and current show. The entirety of the rest of the window is a chatroom, which fills up on the right-hand side with nicknames of attendees (peaking at around thirty during my visit) and with a continuous flow of reactions appearing in the larger left-hand window. Throughout the stream, several attendees mentioned the contexts and timezones in which they were listening; one was cycling back from a clubnight at 7am in Taipei, another was listening at $7 \mathrm{pm}$ and had ordered pizza, another had arrived home from college and was doing lab homework while listening, several alluded to dancing in their homes. The geographical distance between attendees was thus frequently acknowledged, to the extent that sharing their disparate locations seemed to be a core part of the bonding experience between audience members.

The mood in the chat was consistently high, and every new track was received with effusive compliments: 'THANK YOU FOR PLAYING THIS SONG', 'yesyesyesyes', 'this is wild!', as

\footnotetext{
${ }^{41}$ Non Stop NXC (@nonstopnxc), 'What are you doing tomorrow night at 3:30pm Pacific, 6:30pm Eastern, and 11:30pm GMT?', Twitter post, 15 July 2016, <https://twitter.com/nonstopnxc/status/754117039921385472> [accessed 25 July 2016 ].
} 
users posted rhythmic animated gifs, mostly of people and cartoon characters dancing, in the chat at regular intervals throughout the show, seemingly trying to compensate for the disembodied and non-physical nature of the experience by mimicking dance through shared images. DJs tended to remain in the chat throughout their sets, providing commentary, and linking to tracks they had remixed; a particularly noteworthy quality of the event was that there was no sense of any division between producers and fans. The virtual nature of the medium, while clearly at odds with the largely domestic locations in which the music was being received, also aided in entirely breaking down the barrier between artist and listener, in a manner which would be impossible to replicate in a physical location and perhaps requires the sense of disembodiment permitted by an online space. It is worth noting, too, that the online location of the show allowed the DJs an enthusiastic audience which they might have been unable to garner in a physical location, bringing together a physically fragmented group of nightcore fans into a single virtual node.

Internet radio and online communities, such as Datafruits, Soundcloud, and the Nightcore Universe forum, represent what Sarah Thornton refers to as 'micro-media', which she defines as distinct from, and often resistant to, the mass media which is still relied upon by the culture industry at large. ${ }^{42}$ Although Daniel Miller and Don Slater agree that internet micro-media act as a counter to the mainstream to a certain extent, they also point out that they are not apart from mainstream media, but rather a continuous extension of them; not in polar opposition to offline cultures or subcultures, but in a state of entanglement with them. ${ }^{43}$ In this respect, disseminating nightcore through internet micro-media makes perfect sense on a structural level, since both simultaneously position themselves as an alternative to the mainstream culture industry, and rely upon it for their very existence, in nightcore's case outright plundering it for source material. In an interview with Dummy Magazine, mononymous

\footnotetext{
42 Thornton, pp. 158-160.

${ }^{43}$ Daniel Miller and Don Slater, The Internet: An Ethnographic Approach (Oxford: Berg, 2000), pp. 5-6.
} 
producer Liz offers an insight as to the motivation behind this seeming dichotomy; although she refers to vaporwave here, the sentiment is also wholly applicable to nightcore:

The digital rebels. The ones who 'steal' others' music, just to manipulate it and chop it up a bit. That is so fucking punk...It's like how punk bands only knew how to play power chords. It's brilliant. Vaporwave isn't lazy, and neither is punk. I think that these two genres of music are parallel. ${ }^{44}$

The idea of nightcore as an offshoot of punk or post-punk may sound far-fetched, but the scene's attitude to creativity recalls the community mentality of K Records, or late 1970s band the Desperate Bicycles' rallying cry, 'It was easy, it was cheap, go and do it'.45 The virtual nature of nightcore's community is also reflected in the entirely digital technologies used to make it; even when a producer moves beyond the simplicity of Audacity and onto more complex tools, professional-standard audio editing software, such as Ableton Lite, are available at a low price but, crucially, are also frequently pirated, a practice which Ableton's CEO Gerhard Behles even acknowledges 'has benefits [...] it helps spread the program tremendously'.46 A producer without disposable income may, then, be able to make electronic music, since hardware other than a laptop (which 93\% of teenagers and young people already have access to) or other computer is not required. ${ }^{47}$ Physical instruments and formal training in production are unnecessary and not expected, and numerous tutorials are available for novice producers to access online; a search for 'Ableton tutorial' on YouTube brings up no fewer than four hundred thousand results. ${ }^{48}$ This is not only applicable to the nightcore scene, and indeed a novice

\footnotetext{
${ }^{44}$ Russell Thomas, 'Next: New Generation', Dummy Magazine (15 November 2013) <http://www.dummymag.com/features/ next-saint-pepsi-and-new-generation> [accessed 21 July 2016].

${ }^{45}$ See Amy Spencer, DIY: The Rise of Lo-Fi Culture (London: Marion Boyars, 2005), pp. 232-235; Simon Reynolds, Rip It Up and Start Again: Postpunk 1978-1984 (London: Penguin Books, 2005), pp. 30-31.

${ }^{46}$ Ableton, 'Products: Live Lite', Ableton Live <https://www.ableton.com/en/products/live-lite/> [accessed 25 July 2016]; Brock Cardiner, 'Ableton CEO Gerhard Behles Talks Killing Your Darlings, Piracy and More', High Snobiety (14 October 2014) <http://www.highsnobiety.com/2014/10/14/ableton-ceo-gerhard-behles-interview/> [accessed 25 July 2016] (para. 32 of 33).

47 Mary Madden, Amanda Lenhart, Maeve Duggan, Sandra Cortesi, and Urs Gasser, 'Teens and Technology 2013', Pew Research Center (13 March 2013), pp. 2-19 (p. 2) <http://www.pewinternet.org/files/old-media/Files/Reports/2013/ PIP_TeensandTechnology2013.pdf> [accessed 25 July 2016].

48 'Search: Ableton Tutorial', YouTube, <https://www.youtube.com/results?search_query=ableton+tutorial> [accessed 25 July 2016].
} 
electronic producer in any genre may make use of these accessible virtual resources, but examining how they operate in this small micro-subcultural context acts as a useful illustration which may, as Reddington suggests, be extrapolated to future research. The centring of the virtual in the nightcore community not only permits a broader global reach, allowing a smallscale micro-subculture a sense of community, but reduces the capital, or resources, required to participate in a style of production with an already low barrier to entry.

\section{Conclusions}

This is only an initial investigation into a burgeoning micro-subculture which, despite its decade-long history and roots as, perhaps, the first internet-born music scene, remains completely untouched in academia. Much of the nightcore scene's ethos, embracing amateurism and fiercely independent in its models of distribution and performance, borrows from earlier do-it-yourself subcultures such as punk, but it is also wholly grounded in contemporary, neo-liberal late capitalism, where the physical and digital are blurred to the point of invisibility across multiple sites of reception. Here, subcultural producers possess an ambivalent relationship with the mainstream music industry which is at once reverent and irreverent, reliant and resistant, born out of affection and enacted through outright cultural theft. Nightcore exists as a musical manifestation of what James Bridle and Bruce Sterling name the 'New Aesthetic', which, particularly in reference to visual art, concerns 'an eruption of the digital into the physical', and focuses above all upon the penetration of the digital into the everyday. ${ }^{49}$ It is perhaps no coincidence that nightcore can be defined chiefly by its speed and by its relationship with the World Wide Web; the internet has rendered the flow of information we live with day-to-day fast-paced enough that geographical distance between

\footnotetext{
49 James Bridle, 'The New Aesthetic: Waving at the Machines', Web Directions South 2011: The Australian Web Industry Conference, Sydney, 11-14 October 2011 <https://www.webdirections.org/resources/james-bridle-waving-at-the-machines> [accessed 25 July 2016]; Bruce Sterling, 'An Essay on the New Aesthetic', Wired (2 April 2012) <http://www.wired.com/ 2012/04/an-essay-on-the-new-aesthetic/> [accessed 25 July 2016].
} 
individuals is stripped of its importance. Nightcore is both reliant upon that rapid informational flow for its source material and community growth, and mirrors it in the frenetic pace of its sound.

Further research might adopt a more in-depth ethnographic approach to nightcore, interviewing individuals about their involvement in the scene and perhaps creating music in the genre as a participatory element of research, since the boundary between producers and observers in nightcore seems to be almost non-existent. I have adopted an observation-based approach here, due mainly to a desire to gain as broad a view of the scene as possible before future comprehensive research is conducted, but suggest that a great deal could be gained from a closer understanding of the lived experiences and insights of enthusiasts who are active within the scene. Although I have touched on the matter here, I would suggest that a more in-depth examination of nightcore from an accelerationist perspective is also required; speed, technology, and an ambivalent relationship with late capitalism are central both to nightcore's aesthetic, and to accelerationist philosophy, and it would be remiss not to explore the former more deeply using the latter as a framework. Further consideration of the feminist, queer, and otherwise politically resistant potential of nightcore is also a possible avenue for further research; the scene is replete with producers whose identities are often marginalised in mainstream music, but who are sufficiently influential to steer the scene. What nightcore can teach us about contemporary micro-subcultures, amateur music production, and community in the era of the New Aesthetic remains to be seen, but it nonetheless appears a fruitful site for further exploration. Nightcore appears to rejoice in its physically disparate producer-consumers' ability to come together online at all hours of the day or night, to share what they have made regardless of experience or skill, to develop their production in a positive and non-judgmental environment, and to negotiate in a public space their complex relationships with contemporary society, corporate industry, and popular music. Far from being hindered by the absence of a geographical centre, the nightcore scene has made a virtue of its own virtuality. 


\section{Bibliography}

Ableton, 'Products: Live Lite', Ableton Live <https://www.ableton.com/en/products/live-lite/> [accessed 25 July 2016]

Agzarian, Nina, '\#WCW: Ducky', NLV Records (13 January 2016) <http://www.nlvrecords.com/ wcw-ducky/> [accessed 25 July 2016]

Allington, Daniel, Byron Dueck, and Anna Jordanous, 'Networks of Value in Electronic Music: SoundCloud, London, and the Importance of Place', Cultural Trends, 24.3 (2015), 211-222 <https://doi.org/10.1080/09548963.2015.1066073> [accessed 25 July 2016]

Babeisland, all i need (online audio recording), SoundCloud, 30 June 2015, <https:// soundcloud.com/babeisland/all-i-need> [accessed 25 July 2016]

Barker, Kristy, 'Ducky: "Nightcore is the nicest scene l've ever participated in", Dummy Magazine (23 March 2016) <http://www.dummymag.com/features/ducky-nightcoreinterview> [accessed 25 July 2016]

Berry, Jonah, 'Nest HQ's Guide to Nightcore', Nest HQ (7 August 2015) <http://nesthq.com/ nightcore> [accessed 21 July 2016]

Bridle, James, 'The New Aesthetic: Waving at the Machines', Web Directions South 2011: The Australian Web Industry Conference, Sydney, 11-14 October $2011<\mathrm{https}: / /$ www.webdirections.org/resources/james-bridle-waving-at-the-machines> [accessed 25 July 2016]

Cardiner, Brock, 'Ableton CEO Gerhard Behles Talks Killing Your Darlings, Piracy and More', High Snobiety (14 October 2014) <http://www.highsnobiety.com/2014/10/14/ ableton-ceo-gerhard-behles-interview/> [accessed 25 July 2016] 
Challis, Mike, 'The DJ Factor: Teaching Performance and Composition from Back to Front', in Music Education with Digital Technology, ed. by Pamela Burnard and John Finney (London: Continuum, 2009), pp. 65-75

Crook, James, Richard Ash, Roger Dannenberg, Benjamin Drung, Vaughan Johnson, Paul Licameli, Leland Lucius, and Martyn Shaw, 'Audacity: A Free Multi-Track Audio Editor and Recorder', Sourceforge (20 January 2016) <https://sourceforge.net/projects/ audacity/> [accessed 25 July 2016]

Datafruits FM <http://datafruits.fm/> [accessed 25 July 2016]

DJ Clickbait, n3v3r fOrg3t u (online audio recording), SoundCloud, 11 June 2016, <https:// soundcloud.com/djclickbait/n3ver-fOrg3t-u> [accessed 25 July 2016]

EasyFun, easyFun - easyMix (online audio recording), SoundCloud, 30 June 2016, <https:// soundcloud.com/easyfun/easymix> [accessed 25 July 2016]

Fan Fiction, 1 w4nt $\cup 2$ KnOw (online audio recording), SoundCloud, 9 April 2015, <https:// soundcloud.com/fanfiction/1-w4nt-u-2-knOw> [accessed 25 July 2016]

_. b3g1n 4g41n (online audio recording), SoundCloud, 10 March 2015, <https:// soundcloud.com/fanfiction/b3g1n-4g41n> [accessed 25 July 2016]

— $f 4 k 3$ (online audio recording), SoundCloud, 28 June 2016, <https://soundcloud.com/ fanfiction/f4k3> [accessed 25 July 2016]

Feinberg, David R., Lisa M. DeBruine, Benedict C. Jones, and David I. Perrett, 'The Role of Femininity and Averageness in Aesthetic Judgments of Women's Voices', Perception, 4.37 (2008), 615-623 <https://doi.org/10.1068/p5514> [accessed 25 July 2016] Harper, Adam, 'The Online Underground: A New Kind of Punk?', Resident Advisor (22 September 2014) <https://www.residentadvisor.net/features/2137> [accessed 25 July 2016] 
Harshman, Heath, 'Why We Welcome Nightcore As The Next Breakout Genre', Dance Music Northwest (25 July 2015) <http://dancemusicnw.com/why-we-welcome-nightcore-asthe-next-breakout-genre/> [accessed 25 July 2016]

Henrik The Artist, Just Peachy (online audio recording), SoundCloud, 14 November 2015, <https://soundcloud.com/henrik-the-artist/just-peachy> [accessed 25 July 2016] Imran Khan, Fall Out Boy-Centuries (Sped Up To Right Amount) (online video recording), YouTube, 11 November 2014, <https://www.youtube.com/watch?v=-qzWRnlYOdo> [accessed 25 July 2016]

Internetparty, Last Time, (online audio recording), SoundCloud, 5 June 2015, <https:// soundcloud.com/internetparty/last-time> [accessed 25 July 2016]

James, Robin, Resilience \& Melancholy: Pop Music, Feminism, Neoliberalism (London: Zero Books 2015)

Kirby, 'What is Nightcore?', Nightcore Universe (8 August 2011) <http:// www.nightcoreuniverse.net/viewtopic.php?f=17\&t=930> [accessed 25 July 2016] Loza, Susana, 'Sampling (Hetero)Sexuality: Diva-Ness and Discipline in Electronic Dance Music', Popular Music, 20.3 (2001), 349-357 <https://doi.org/10.1017/ S0261143001001544> [accessed 25 July 2015] Madden, Mary, Amanda Lenhart, Maeve Duggan, Sandra Cortesi, and Urs Gasser, 'Teens and Technology 2013, Pew Research Center (13 March 2013), pp. 2-19 <http:// www.pewinternet.org/files/old-media/Files/Reports/2013/ PIP_TeensandTechnology2013.pdf> [accessed 25 July 2016] Maikel631, 'How to Nightcore a song! (NIGHTCORE TUTORIAL)', Nightcore Universe (8 May 2010) <http://www.nightcoreuniverse.net/viewtopic.php?f=15\&t=142> [accessed 25 July 2016] 
_. Amazing Nightcore and Trance (online video recording), YouTube, 25 July 2016, <https://www.youtube.com/user/Maikel6311> [accessed 25 July 2016]

Marcus, George E., 'Ethnography in/of the World System: The Emergence of Multi-Sited Ethnography', Annual Review of Anthropology, 24 (1995), 95-117 <https://doi.org/ 10.1146/annurev.an.24.100195.000523> [accessed 25 July 2016]

Miller, Daniel, and Don Slater, The Internet: An Ethnographic Approach (Oxford: Berg, 2000) Non Stop NXC (@nonstopnxc), 'What are you doing tomorrow night at 3:30pm Pacific, 6:30pm Eastern, and 11:30pm GMT?', Twitter post, 15 July 2016, <https://twitter.com/ nonstopnxc/status/754117039921385472> [accessed 25 July 2016]

'Non Stop Pop', NTS Live <http://www.nts.live/shows/jack> [accessed 25 July 2016]

Pepsi, SoundCloud, <https://soundcloud.com/not_pepsi> [accessed 25 July 2016]

Pepsi Cola, YouTube, <https://www.youtube.com/channel/UCxNBvCX1cy5f8whl07mRCIA> [accessed 25 July 2016]

Reddington, Helen, '"Lady": Punks in Bands: A Subculturette?', in The Post-Subcultures Reader, ed. by David Muggleton (Oxford: Berg, 2013), pp. 231-251

Reynolds, Simon, Rip It Up and Start Again: Postpunk 1978-1984 (London: Penguin Books, 2005)

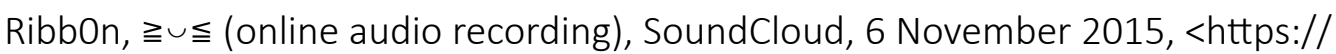
soundcloud.com/ribb0n/alive> [accessed 25 July 2016]

Rodgers, Tara, Pink Noises: Women on Electronic Music and Sound (Durham, North Carolina: Duke University Press 2010)

'Search: Ableton Tutorial', YouTube, <https://www.youtube.com/results? search_query=ableton+tutorial> [accessed 25 July 2016] 
Sharples, Staley, 'PressPlaylist: Surati's NXC Sounds', PressPlay (29 April 2016) <https:// wearepressplay.com/2016/04/29/pressplaylist-suratis-nxc-sounds/> [accessed July 25 2016]

Spencer, Amy, D/Y: The Rise of Lo-Fi Culture (London: Marion Boyars, 2005)

Sterling, Bruce, 'An Essay on the New Aesthetic', Wired (April 2 2012) <http:// www.wired.com/2012/04/an-essay-on-the-new-aesthetic/> [accessed 25 July 2016]

'Statistics', YouTube, <https://www.youtube.com/yt/press/en-GB/statistics.html> [accessed 31 October 2016]

Tannen, Deborah, 'Marked Women, Unmarked Men', The New York Times Magazine, 20 June 1993, pp. 1-4

Tanner, Grafton, Babbling Corpse: Vaporwave and the Commodification of Ghosts (London: Zero Books, 2016)

Thomas, Russell, 'Next: New Generation', Dummy Magazine (15 November 2013) <http:// www.dummymag.com/features/next-saint-pepsi-and-new-generation> [accessed 21 July 2016]

Thornton, Sarah, Club Cultures: Music, Media, and Subcultural Capital (Cambridge: Polity 1995)

Underdog, internetparty \& underdOg - home (online audio recording), SoundCloud, 15 October 2015, <https://soundcloud.com/underdOge/home> [accessed 25 July 2016] 